\title{
Die reisende prediker as profeet in die S.A. samelewing II (vervolg)
}

Dr. J. L. Venter

Die reisende predikers met hul groot tente in die Suid-Afrikaanse samelewing herinner aan die vroeëre reisende predikers van die Nuwe Testament. Op die oog af skep hulle ook die indruk asof hulle die werk voortsit. Ondersoek wat in die verlede deur dagblaaie, individuele gelowiges en skrywers in korrespondensiekolomme van tydskrifte geloods is, loop gewoonlik net op 'n dooiepunt uit. Die kerk bly nog altyd sy lidmate 'n antwoord skuldig ten opsigte van 'n Skrifgefundeerde standpunt oor hierdie bedieningspraktyk.

Videomateriaal van twee eksponente van hierdie bedieningspraktyk, naamlik Nicky van der Westhuizen en Neels Prinsloo van die Christelike Sentrum in Pretoria is gebruik in die ondersoek. (Van der Westhuizen 1984 a. b, $c$ en Prinsloo, 1985 a, b, c).

\subsection{BETER BEKEND AS 'EVANGELISTE'}

Hulle optrede is egter duidelik gekenmerk deur die tipiese elemente van vroeëre Nuwe-Testamentiese profete se werksaamhede:

1. Appellerende uitsprake. "Ons bring hier 'n ontmoeting met die bonatuurlike" (Prinsloo, 1985a:486).

2. Besondere insig: gesindhede, agtergrondsomstandighede. "Met 'n woord van kennis wys God my dat hier (in die tent) sewe besigheidsmanne is wat binne 3 maande ' $n$ finansiële deurbraak gaan maak . . . (Van der Westhuizen 1984b:99).

3. Insig in die toekoms: " . . dat na hierdie veldtog die area (Klerksdorp) sal lewe!" (Van der Westhuizen, 1984c:438).

4. Aanspraak op bonatuurlike genesings: "Ek beloof $u$ sal nooit weer dieselfde wees nie" (Van der Westhuizen, 1984c:438).

\subsubsection{Sy roeping en opdrag}

Albei ontvang tydens spesifieke geleenthede in hul lewe 'n duidelike roeping van God om 'n besondere boodskapper en bediener van genesing te wees (Prinsloo, 1985a 486). Egter net soos by alle ander profete onkontroleerbaar.

Hy sien dit as sy opdrag om die Suid-Afrikaanse samelewing tot herlewing te bring, om mense uit die natuurlike vlak uit te ruk tot die bonatuurlike en Jesus se genesingswerk voort te sit. "As Hy nie vanaand dieselfde van 2000 jaar terug kan doen nie, is Hy nie dieselfde nie, dan is Hy 'n leuenaar"' (Prinsloo, 1985b:488).

\subsubsection{Sy prediking}

Die hooftema van die prediking handel telikens oor 'n onderwerp wat die werklikheid en wenslikheid van genesingswonders by die hoorders beklemtoon. Hy beklemtoon telkens sekere voorwaardes en voorskrifte vir genesing. "Die fout wat kerke doen, hulle sluit die diens na die Woord- 
(verkondiging) af - nog voordat mense iets kan ontvang . . u is nou eers gereed om te ontvang!" (Prinsloo, 1985b 488). Die prediking staan ondergeskik en aanlopend tot die hoogtepunt, naamlik genesings.

\subsubsection{Enkele voorwaardes en voorskrifte voor genesing}

1. Die hoorder moet hom buig onder die krag van die gebed.

2. Opgeruimd - sang bring God in beweging (Josafat, 2 Kon $20: 1-30$ ).

3 . Oliesalwing onontbeerlik vir genesing.

4. Moet glo dat Jesus nou nog kan genees - 'n geloof wat nou volle genesing moet opeis.

5 . Totale gehoorsaamheid sodat die hoorder voortaan sy tiende sal bring en siele sal wen vir die Here en sorg vir mense sodat die tent te klein word (Van der Westhuizen, 1984a:297).

6. Moet nie die woorde van die profeet probeer verstaan nie, moet dit net glo en aanvaar.

7. Moet breek met die tradisionele siening van die 'historiese kerke' dat genesing nie meer kan plaasvind nie.

\subsubsection{Bykomende elemente vir die nodige stemming}

Hoorders word stelselmatig voorberei tot 'n sekere ontvanklikheid waaroor hulle nie normaalweg beskik nie, en waar hulle hul uiteindelik spontaan aan enige gebeurlikheid oorgee.

- "nie normale erediens nie . . swaai jou sakdoek . . . Jy is bang jou dominee staan agter jou" (Prinsloo 1985a 486: 1985b:488).

- musiek, sang en handbewegings, herhalende clichés.

\subsubsection{Genesings}

Belangrikste element en wek groot belangstelling. Prosedure, voorbereiding, val.

\subsection{VERWAGTINGE VAN HOORDERS IN SUID-AFRIKA}

Die gelowige se godsdiens moet geloof waardige antwoorde op die realiteite van elke dag bied. Dit maak nie saak hoe abstrak die formulering van ' $n$ religieuse sisteem is of hoe onverklaarbaar sekere seremoniele rites is nie, solank die godsdiens net vir die volgelinge die gevoel gee dat dit sinvol meespreek tot hulle algemene daaglikse bestaan (Oosthuizen et al., 1985:9). Wanneer die Afrikaanse Kerke nie by magte is om antwoorde en oplossings te bied wat vir 'n gelowige aanvaarbaar is volgens sy eie vooropgestelde verwagtinge nie, kan dit gebeur dat die gelowige hom eerder gaan toespits op dit wat wel na sy mening 'n antwoord kan bied en op ' $n$ manier tog nog aan sy eie religieusiteit uitdrukking gee.

Politieke struktuurveranderinge, ekonomiese terugslae, sosio-maatskaplike en daaglikse persoonlike krisisse en lyde staan nog vol op die agenda. Dit lei daartoe dat gelowiges wat normaalweg gelukkig is in hul kerk met een of ander aspek van sy lewensproblematiek hom skielik wend tot ' $n$ alternatiewe godsdiensbeoefening wat moontlik antwoorde kan bied sonder aflegging van sy lidmaatskap in sy plaaslike kerk (Smuts et al., 1982:45v).

Besoekers by so 'n groot tent neem net elemente oor wat hulle verwagtinge kan bevredig en wat hulle nie by hulle eie kerk vind nie (vgl Greil. $1977: 116$ ). 


\section{In die Skriflig}

Genesing van fisiese kwale of bevryding van spanning is van die verwagtinge wat baie mense vervul wil sien en die reisende profeet bied daardie moontlikheid. Daarom doen sommige mense mee aan dinge waärmee hulle hul vıoeer nooit sou geassosieer het nie.

Die reisende profeet slaag uitmuntend met die gebeure in die groot tent daarin om die behoeftes van sy hoorders raak te formuleer en hulle tree vir tree tot vervulling te lei.

- Vir die eerste keer voel gelowiges uit historiese kerke nie selfbewus oor spontane geloofsbelewing met ekstatiese uitinge nie.

- Hier word kontak met God 'n werklikheid.

- Vir die eerste keer sien hulle Jesus se kragte as 'n werklikheid in beweging.

- Hier hoor hulle weer die onverskrokke en selfs uitdagende aanspraak van God se profete.

- Vir die eerste keer smaak hulle die oorwinning oor siekte, finansiële drukte en geestelike aanvegtinge.

\subsection{TERUGVOERING EN REAKSIE OP DIE REISENDE PROFEET}

Hy ondervind 'n tweeerlei reaksie:

1. Van die hoorders in die tent.

2. Van die res van die Suid-Afrikaanse samelewing.

\subsubsection{Hoorders in die tent}

Omdat sy optrede juis die vervulling is van hul verwagtinge, ondervind die reisende profeet geen teenkanting of afwysing soos wat 'n profeet dit moet verwag nie. Hy meet ook gereeld die emosionele lading van die samekoms met vrae soos "Is u nog hier met my, my vriend, kom ons klap hande" (Van der Westhuizen, 1984c:438).

Die enkeles wat kritiek mag lewer is nie 'n bedreiging nie, want hy het nog genoeg ander aanhangers.

\subsubsection{Kritiek uit die res van die samelewing}

- Mense uit die samelewing beweer dit is alles bedrog.

- Mense beweer dat die geneser nie sy werk aan objektiewe mediese toetsing wil onderwerp nie.

- Siekes word onder emosionele druk finansieel uitgebuit.

In vorige profetiese prosesse is gesien dat die ware profeet onmiddellik regstellings op valse verwagtinge maak. Wat is die reisende profeet se reaksie?

\subsection{REGSTELLING OP SY HOORDERS}

\subsubsection{Hoorders in die groot tent}

Geen regstelling is hier nodig nie, almal tevrede (vgl. Herder van Hermas).

\subsubsection{Die profeet se reaksie op kritiek uit die samelewing}

1. Geen wins vir hom om hom in die openbare nuusmedia bloot te stel nie. Sy volgelinge van wie hy afhanklik is, is in elk geval ten volle oortuig van sy bona fides.

2. Negatiewe publisiteit verander nog nie die verwagtinge van die tenthoorders nie (vgl. Theo Wolmarans).

3. Kritiek van buite gee aan die reisende profeet net meer rede om aan sy volgelinge in die tent wat hom vertrou, te illustreer hoe satanies, 
vol leuens en onkundig die kerk en wêreld daar buite is. Kritiek van buite is net besig om die werk van die Gees teen te staan (Prinsloo, $1985 \mathrm{~b}: 488$ ).

4. Die reisende profeet sal hoogstens met 'n verklaring sonder verdere polemiek oor die saak in die openbare pers volstaan. Sy volgelinge sien dit as 'n regstelling en dat die wêreld nou bewus moet wees van die waarheid oor hul prediker.

Enige weerstand word as duiwelswerk beskou. "Die Satan sal nie naby hierdie veldtog kom nie, want hier is te veel lig" (Van der Westhuizen. 1984b:99).

\subsection{EVALUERING VAN DIE REISENDE PROFEET IN DIE SUID-AFRIKAANSE SAMELEWING}

Overholt se model kan hier toegepas word want al drie komponente van die profetiese proses naamlik God, profeet en hoorders is teenwoordig.

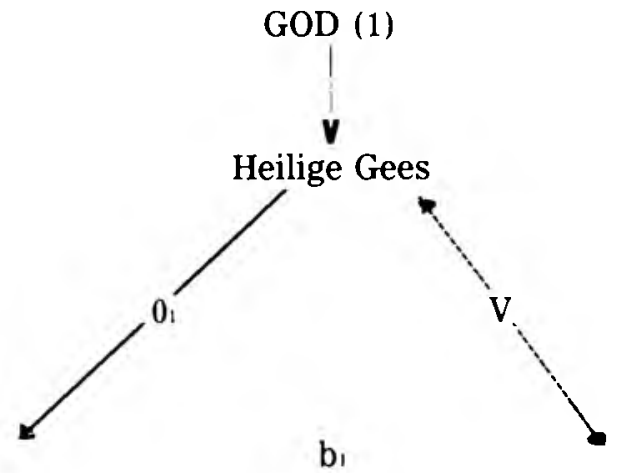

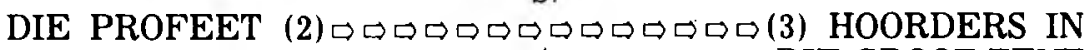
DIE GROOT TENT

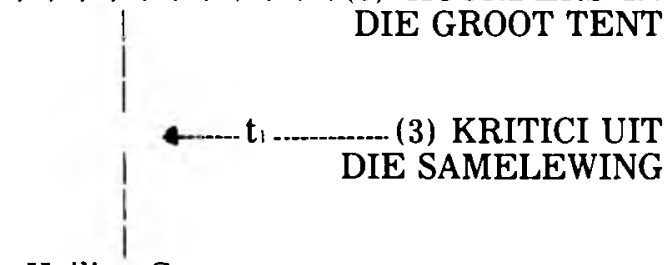

Heilige Gees

DIE PROFEET (2)

(3) DIE KERK (ALLE GELOWIGES)

8.5.1 Interaksie tussen God en die profeet $(1,2,1)$

- Nie 'n probleem want sy hoorders aanvaar sy aanbieding as ' $n$ boodskapper van God. 
8.5.2 Interaksie tussen die reisende profeet en sy hoorders $(2 \circlearrowleft 3 \bullet 2)$

$b_{1}(2 \square 3)$ Boodskap gesalf met Heilige Gees.

- Klem val op individu se persoonlike ervaring van genesing en bevryding.

- Gerig op voorbereiding tot finale doelwit naamlik genesings.

$\mathrm{t}(3 \not 2)$ Die hoorders in die tent het gekom om sekere gebeure te sien, en wanneer dit dan gebeur gaan hulle dit nie betwyfel nie. Hulle sien dit as werke van die Heilige Gees en wil nie daarteen sondig nie!

(Geen verdere aksie as net lof en dus ontbreek $t$ as terugvoering op diagram).

Resultaat: Hulle twyfel nie daaraan dat die reisende profeet 'n ware profeet van God is nie.

$t_{1}(3 \Rightarrow 2)$ Reaksie uit die res van samelewing

- Besef toedrag van sake laat ruimte vir valse profete om die samelewing te mislei.

- Maar omdat die reisende profeet nie ten volle in diskussie gaan vir objektiewe toetsing nie en hy die kritiek bloot as satanies afmaak, is $2 \Rightarrow 3 \Rightarrow 2$ 'n onvolledige interaksie. Dit stuit teen die "werke van die Heilige Gees" en kom nie by die profeet self uit nie. Hy skuil agter die 'Gees' terwyl hy te midde van negatiewe publisiteit rustig kan voortgaan.

\subsubsection{Regstelling op hoorders $(2 \triangleleft 3)$}

- In tent, nie nodig.

- Op kritiek uit samelewing, nie nodig, skuil agter 'Heilige Gees'.

8.5.4 Interaksie tussen God en die hoorders (3 $c: 1: 3)$

${ }^{K_{V}}=$ aksie van die hoorders in die tent tot God $(3 \square 1)$

- God sal beloftes waarmaak en sal dit in dade van genesing en bevryding bewys.

$V_{y}=$ reaksie van God se openbaring op hoorders $(1 \neg 3)$

- Die Skrifopenbaring gee finale maatstaf om te toets.

- Hoorders moet dus hul verwagtinge eers aan die Skrif toets.

Die Skrif dra die stem van die Heilige Gees en die wil van die Vader.

Die verrassende feit is egter dat in die profetiese proses van die reisende prediker as profeet in sy groot tent in die Suid-Afrikaanse samelewing hierdie finale toetskriterium, naamlik die Skrif, nog deur die hoorders nog deur die kritici in die samelewing nòg deur die profeet self gehanteer word!

Die wese van die reisende prediker se bediening dwing hom om ' $n$ ander hermeneutiese sleutel tot bantering van die Skrif te gebruik, naamlik die inwendige lig van die Heilige Gees in homself as toetskriterium. Dit is 'n duidelike Doperse neiging! Hiermee word die finale toetskriterium, naamlik die Heilige Skrif, soos in alle vroeëre profetiese prosesse in Christelike gemeenskappe gebruik, totaal geignoreer! Die toepassing van hierdie model toon hierdie eensydigheid duidelik aan.

Die werklike situasie in die Suid-Afrikaanse samelewing ten opsigte van hierdie saak is dat die samelewing nog steeds dieselfde fout maak as 
wat in ander profetiese prosesse in gemeenskappe gebeur het waar daar nog nie ' $n$ finale toetskriterium beskikbaar is nie. Hulle laat hulle lei deur selfgeformuleerde verwagtinge wat hulle van God koester en pas dit net so toe op die reisende profeet. Die reisende profeet voldoen daaraan en word met eer en bewondering ' $n$ plek in die samelewing toegeken sonder dat werklike toetsing plaasgevind het.

Die situasie is gevolglik in die Suid-Afrikaanse samelewing op die oomblik nog so dat 'n valse profeet lof en eer kan ontvang bloot omdat hy voldoen aan die vereistes van sy hoorders! 'n Ware profeet daarenteen wat profeteer volgens die Woord van God kan in die oe van die gemeenskap waarskynlik geen erkenning kry nie!

\subsection{BEVINDINGE OOR DIE REISENDE PREDIKER AS PROFEET SE POSISIE IN DIE SUID-AFRIKAANSE SAMELEWING}

1. Die reisende prediker as profeet van God beklee 'n eervolle posisie by baie gelowiges. Hy is 'n gewilde figuur en word as ' $n$ man van God deur honderde Suid-Afrikaners bewonder. Hierdie mense bly lojaal teenoor hom. ongeag enige kritiek of aanval op die profeet se werk.

2. Die reisende profeet word veilig beskerm deur selfontwerpte afweermeganismes en beskermingsmaatreëls wat van die begin af in sy bedieningspraktyk ingebou word.

3. Hy verkeer in 'n 'onaantasbare posisie' waar geen kritiek of aanvalle van buite sy veilige beskutting tussen sy lojale bewonderaars kan aanraak of vernietig nie.

4. Hy bevind hom in 'n posisie waar hy 'n oop mandaat het om enigiets as die Woord van God te verkondig, mense op watter wyse ook al te genees, met sukses of mislukking, sonder om iewers of aan enige instansie verantwoording te doen

5. Hy bevind hom in 'n posisie waar alleenlik sy eie gewete voor God, hoe broos dit ook al mag wees, kan verhoed dat hy met mag- en eerwellus onkundige mense emosioneel manipuleer en finansieel verarm.

6. Dit sou 'n oortreding van die negende gebod wees om in die huidige konteks van die Suid-Afrikaanse samelewing die reisende profeet sonder meer as ' $n$ valse profeet wat hom op die Suid-Afrikaanse samelewing afdwing, te beskuldig. Die valsheid en onkundigheid het sy oorsprong op 'n ander vlak. Die reisende profeet is maar net 'n reaksie daarop. Die eintlike oorsaak van al die ervare verdriet en teleurstelling van mense met hierdie soort bedieningspraktyk, en al die verwarring by kerklidmate, is net as gevolg van die gelowiges se eie onkunde oor die toetskriteria van die Skrif. Hierdie toestand is ' $n$ onbetaalde rekening van die historiese kerke. Dit is die 'gelowige volkere van Suid-Afrika' wat duidelik 'n behoefte openbaar en geleenthede skep vir so 'n figuur om met die rolvertolking van 'n profeet die 'gelowiges' se selfontwerpte verwagtinge te vervul. Die reisende profeet sien die geleentheid fyn raak, reagecr daarop en stel hom beskikbaar om aan daardie verwagtinge te voldoen. Terselfdertyd dien dit as 'n goeie beroep om 'n lewe van te maak! Dit is die skandelike ongeloof in die ware Woord van God, en onkunde van gelowiges, 
wat hierdie geleenthede skep waardeur valshede en onbybelse manipulasie 'n greep op 'n deel van die samelewing gekry het.

7. Hierdie bevoorregte en beskutte posisie waarin die reisende profeet geld maak met Jesus Christus sal hy met goeie vooruitsigte kan bly behou, omdat die volk nog nooit geleer het om die Skrif te hanteer en dit alleen as die finale toetskriterium teenoor alle profete te gebruik soos dit gedoen mót word nie.

8. Alle pogings in die verlede om hierdie religieuse figure in die samelewing na waarde te weeg, het nog elke keer misluk omdat daar nog nie 'n geslaagde metode was om werklik op Skriftuurlik gefundeerde wyse die reisende profeet te toets nie. Langafstand-pogings deur die nuusmedia bereik niks en kan maklik in onbillike persoonlike aanvalle ontaard.

8.8 REGSTELLING VAN DIE HOORDERS OP DIE PROFEET MET DIE SKRIF AS FINALE DEURSLAGGEWENDE TOETSKRITERIUM $(3 \square 2)$

8.8.1 Ten opsigte van roepingsaansprake:

- Hierdie aanspraak is op sigself nie 'n genoegsame waarborg vir egtheid en geldigheid van optrede nie.

- Elke profeet moet binne gemeentelike verband gekontroleer word en gevolglik staan hierdie manne ook nie bo toetsing en kritiek verhewe nie.

- Wanneer die Kerk hom toets soos in Nuwe Testament aangedui, is daar geen gevaar dat teen die Heilige Gees gesondig sal word nie.

8.8.2 Ten opsigte van sogenaamde suksesvolle resultate

- Volgens die Skrif kan dit nie deurslaggewende faktor wees vir die bepaling van egtheid nie. Valse profete het ook goeie resultate.

\subsubsection{Ten opsigte van sy prediking}

\subsubsection{Voorspellinge en openbaringe}

- Nuwe Testament het aangetoon dat 'n profeet se woorde dadelik getoets moet word aan ander kriteria as die van latere vervulling van voorspellinge.

- 'Nuwe openbaringe' met soteriologiese inhoud, los van en bykomstig tot die Woord van God met 'n nuwe inhoud anders as die oorspronklike verlossingsevangelie is onskriftuurlik al spreek dit die hoorders hoe sterk aan.

\subsubsection{Eensydige beklemtoning van genesing in die prediking}

- Dit is nie volgens die Nuwe Testament die inhoud van 'n profeet se prediking nie

- Dit moet opbouende prediking wees wat gerig word tot die hele gemeente en nie op individuele vervulling van menslike fisiese verwagtinge nie. Kerugmatiese en didaskaliese prediking versterk die geloof wat in 'n gebroke bedeling van lyde die oorwinning alreeds kan smaak.

- Hy verander die inhoud van geloof in die soenverdienste van Christus in 'n geloof met die resultate van genesing as inhoud. 


\subsubsection{Ten opsigte van genesingswonders in hierdie bedeling}

- Die openbaring van God toon dat genesings nie meer die primēre opdrag van God se profete in die gemeente is nie.

- 'n Sug na sensasionele gebeure word deur Jesus met minagting verwerp en ontmasker dit as onvolwasse geloof.

- Wondergenesings beklee volgens die Skrif net aanvullende krag ter bevestiging van die vroeëre ongeskrewe openbaring van God. Met die Skriftelike openbaring ter hand weet elke gelowige dat sy finale verlossing in Jesus Christus verseker is. Wonders hoef dit nie meer te bewys nie.

- Die Skrif wil nie so 'n verwagting by gelowiges skep nie. Gevolglik tas hierdie bedieningspraktyk die genoegsaamheid van die Skrif aan, misken die eie aard en krag van Bybelse geloof en verloèn die daaglikse leiding en bystand van die Heilige Gees.

8.8.5 Ten opsigte van sy voorbereidende handelinge met die oog op genesing

- Volgens God se openbaring in die Evangeliebeskrywinge en die boek Handelinge waar genesings nog 'n deel van die profeet se werksaamhede was, is daar geen sprake van musiek en sang, opgeruimdheid, handeklap en tale as voorbereiding nie.

- Oliesalwing dui op ' $n$ wyse waarop genesing geskied, maar word nooit in die Skrif as voorwaarde vir genesing aangedui nie.

- Bybelse geloof eis nie met soveel brutaliteit genesing nie, en gebruik God nie net as 'n instrument tot genesing nie.

8.8.6 Ten opsigte van die profeet se posisie buite die gemeentelike samekoms

- Die openbaring van God toon dat 'n profeet juis binne die gemeentelike samekoms optree waar hy getoets kan word. So alleen kan regstellings onmiddellik geskied.

\subsection{SAMEVATTENDE KONKLUSIE}

Die kerk van Jesus Christus is verplig om bogenoemde regstelling ten opsigte van hierdie bedieningspraktyk te maak. Die kerk moet in die eerste plek op die Skrifkriteria gewys word waarvolgens hierdie bedieningspraktyk van reisende profete beoordeel en geweeg moet word. Indien die reisende profete in die Suid-Afrikaanse samelewing op bogenoemde Skriftuurlike toetsing sy optrede en doelwitte wysig, sal die waarheid van die Skrif seevier. Indien hy egter met sy praktyk voortgaan soos dit uiteengesit is, kan sy optrede nie anders as vals en misleidend bestempel word nie.

Die rol en funksie van die reisende prediker as profeet het in hierdie studie egter duidelik aangetoon dat hy hom nooit aan hierdie toetsing kan onderwerp nie.

Sy hele bedieningspraktyk, sukses en toekomstige bestaan hang af van die dinge wat juis reggestel moet word volgens die Skrif:

1. Die geldigheid en gesag van sy roepingsaansprake.

2. Die gedagte dat hy bo kritiek verhewe is

3 . Sy prediking eensydig toegespits op genesing.

4. Die oordrewe eskatologiese verwagtinge wat hy sou vervul. 


\section{In die Skriflig}

5. Sy eensydige beklemtoning van fisiese genesingswonders.

6. Sy optrede buite die gemeentelike samekoms waar hy ongekontroleer in die versoeking gestel kan word om liggelowiges te mislei.

Die skrywer kan nie anders nie as om te konkludeer dat die bedieningspraktyk van reisende predikers as profete met hul groot tente op geen Skrifgefundeerde gronde op die eervolle plek en posisie kan aanspraak maak wat hulle tans geniet nie. Hulle beklee 'n posisie en vertolk'n rol wat mense met valse verwagtinge van die Skrif vir hulle geskep het en wat nie uit die Skrif te verantwoord is nie.

Die kerk sal hierdie gevaar van misleiding moet uitwys. Die kerk sal sy roeping versaak as hy hierdie regstelling nie maak nie. 